\title{
On Application of Formative Assessment in Teaching Japanese as a Second Language
}

\author{
Xuejing He \\ College of Foreign Languages and Cultures, Sichuan Minzu College, Kangding, Sichuan, 626001 \\ E-mail: daphne315@163.com
}

Keywords: formative assessment; teaching and learning activities; teaching Japanese as a second language

\begin{abstract}
To take Sichuan Minzu College as an example, this paper demonstrates the current assessment in Japanese teaching, and elaborates the necessity of formative assessment in reform and practice in teaching Japanese as a second language. Through specific teaching and learning activities, the result of practice of formative assessment is an act of enlightening for further study on it.
\end{abstract}

\section{The Current Assessment in Japanese Teaching}

Teaching assessment is an evaluation technique in judging the teaching goals. Focused on the teaching target, teaching assessment observes and analyzes the teaching process and teaching effect. In College of Foreign Languages, the current teaching assessment in Japanese teaching is summative assessment, which focuses on the outcome of a unit, a program or the entire course. The current summative assessment is inclined to be more teacher-led. The learners are not put in the core of the assessment process. Marks are given to the students, which indicate their performance on study. However, every student has the right to evaluate and the right to know how well they are doing. The students should not be judged by simple marks. They need to know if they are progressing from what they have previously done.

The evaluation system should carry meaning for students and help them to learn better, should make the student progress and help them advance, and should help teachers to teach better. With the converting concept of Japanese teaching theory, the improvement of evaluation system becomes the heart of Japanese teaching reform ${ }^{[1]}$. The summative assessment should not be the only evaluation. It's necessary to explore the formative assessment in Japanese teaching.

\section{The Practice of Formative Assessment}

\subsection{The Introduction of Formative Assessment}

Formative assessment, including diagnostic testing, is a range of formal and informal assessment procedures conducted by teachers during the learning process in order to modify teaching and learning activities to improve student attainment ${ }^{[2]}$. Formative assessment involves close attention on teaching and learning, on the detailed progress of learning, rather than the final test score.

Contrasted with summative assessment, the formative assessment has three distinctive characteristics, which are the active learning motivation, the multiple assessment subjects and the bilateral assessment process. Firstly, it stimulates the motivation of learning. The will of learning get strengthened, the interest of learning get inspired and the feedback of learning get fully used. Secondly, it's no longer the teacher-centered judgment; the students join in the assessment, be in groups or on one's own. This can encourage the self-study, strengthen the communication among learners and form a three-dimensional learning pattern. Finally, the assessment between students and teachers can help to identify the deficiencies in individual or in group, and can provide feedback for teachers to modify the teaching contents and learning activities. The assessment among students can cultivate the ability to discover problem, research problem and settle problem, 
and can promote the use of Japanese.

The formative assessment is not purely marks-referenced. It moves focus onto teaching and learning process, and improve the learners' awareness of what they learn and how they learn. Compared to the current summative assessment in Japanese teaching, the formative assessment is performed to better meet the learning target as well as cultivate the learners' comprehensive Japanese application.

\subsection{The Strategy of Formative Assessment}

A serious of reform for formative assessment has been designed to improve learning. The teacher-centered assessment switches to the student-centered assessment. The self-assessment and the group-assessment are encouraged. This reform performs in the $6^{\text {th }}$ semester and takes the students of grade 2014, 4 classes, totally 130 people, as research target. The textbook is New Sino-Japanese Communication Standard Japanese (Elementary 1). The teaching contents are from lesson 5 to lesson 10. Each lesson covers 6 parts, including Sentence Patterns, Dialogues, Grammar, Words and Expressions, Japanese Culture and Exercises. Each lesson is attached with plenty of exercises to consolidate the vocabulary and grammar that have been learned in that unit. The teacher should focus on the observation, research and analysis, while the students are mainly doing the recording, feedback and conclusion.

The formative assessment covers $30 \%$ grades and consists of the performance of speaking, the self-assessment for listening and the group-assessment for homework. The performance of speaking covers $3 \%$. The students are encouraged to speak Japanese in class and are welcomed off the class, like answer the questions, read the textbook, greetings, make dialogues, and sing a song. The self-assessment for listening covers $3 \%$. The students are required to finish the listening practice, complete the dictation and check the answer by themselves. The group-assessment for homework covers $24 \%$. The class is divided into 6 groups. Each group takes responsibility to set the criteria of the exercises, correct the answers and finish the records of marking, including the errors in the exercise, the exercise examination of the whole class and the evaluation of the exercise.

The formative assessment takes into account the progress of each learner and the positive intent of fulfilling the effort. The learners have to be active in formative assessment and in their study. In the new assessment, the teachers can then analyze the problems in the study and modify the teaching contents and methods, while the students may change their study habits and improve their study efficiency.

\section{The Feedback and the Teaching Reflection}

\subsection{Interviews on formative assessment}

Feedback between students and teachers is crucial in formative assessment. Whether the reform previously mentioned meets the students' need, feedback on the reform is valuable for further teaching. In order to figure out the practicability and validity of formative assessment, interviews are organized 4 times for each class, including 47 students. Questions are as follows:

(1) Do you think formative assessment is practical? What's your reason?

(2) Does it help you to find out the studying problems? What are the problems?

(3) Does it help you to achieve the learning goals? How do you define it?

(4) Does it help you to intrigue self-study? How do you explain it?

(5) Does it help you on group-study? How do you explain it?

Students get good understanding of formative assessment as follows:

(1) It is necessary positive in Japanese learning. The enthusiasm and the initiative of Japanese learning are aroused. Believing their ability of self-study, the students do effective jobs to achieve the goals. In the meantime, participation in Japanese culture develops the students' motivation to learn Japanese.

(2) It helps students and teachers to check current status of Japanese learning. Since they know their problems in listening, speaking, reading and writing, the students modify what should be done 
in preview and review study.

(3) It enables the students to realize the goal and criteria for each lesson. The students are aware of the teaching focuses and difficulties, and do the best to keep themselves on the right path to complete their learning goals.

(4) It contributes the success of learning to individual struggle and group effort. Students do a good job in discussion and do a lot of interaction, which provides a chance to express feelings and exchange thoughts. The students become the owner of their own learning.

(5) It proves that peer-assessment have a vital part in it. Students prefer to speak to one who is equal to another in rank and in the same age. The perception or understanding of a classmate is much more welcomed than that of a teacher. The students are inclined to accept advices and criticism from peers than from a teacher.

\subsection{Teaching reflection}

The practice of formative assessment combines effectively teaching and learning, stresses the learners have a leading role in it, is useful for the cultivation of learner's Japanese application, innovative research abilities, team work abilities, and communicative abilities.

The relationship and communication between students and teachers get strengthened. On one hand, formative assessment enables the teachers master the students' learning effect, learning condition, learning emotion and learning requirement. On the other hand, it encourages the students to interact with the teachers, to fulfill the development of self-assessment, and to establish positive self-esteem. However, there still exits several topics to be solved:

(1) The proportion of formative assessment should be increased to $40 \%$.

(2) The Japanese calligraphy should be practiced a lot at the entry-level.

(3) The Japanese input method should be encouraged and promoted.

(4) The effective self-assessment and group-assessment should be facilitated.

(5) The Japanese self-learning record should be detailed and completed.

(6) The Japanese culture and cross-culture should be strengthened and expanded.

(7) The research of Japanese and Japanese culture should be broadened and deepened.

\section{Conclusion}

The mission of Sichuan Minzu College is to aim at achieving excellence in every subject of its teaching and research, maintaining its historical position as a top-class college in Tibetan area in Sichuan Province, enriching the economic development of Ganzi Tibetan Autonomous Prefecture, and equipping the undergraduates to play their role at regional level. In support of this aim the college will cultivate application-oriented undergraduate. Japanese teaching quality plays the vital role in Japanese talent cultivation. It is believed that teaching quality depends on the quality of teaching assessment, if the assessment can be favorably used, then learning would be progressed a $\operatorname{lot}^{[3]}$.

Formative assessment is the central function of Japanese teaching reform. It promotes harmonious and delightful teaching which benefits from a fruitful communication with students and teachers, provides the exchange of ideas through teaching and discussion with the teacher and group learning. The application of formative assessment in teaching Japanese as a second language promotes the mutual progress of both teachers and students, and is the trend of implementation of the comprehensive Japanese application and cross-cultural communicative abilities.

\section{Acknowledgements}

This paper is supported by the project of Sichuan Minzu College. The project name is: Reform and Practice of Teaching Japanese as a Second Language in Institution of Higher Learning in Tibetan Area in Sichuan Province (No.2017xjjg14). 


\section{References}

[1] Peng Jin, Xu Minmin. Insights into the Reform of Japanese Language Classroom Teaching in China [J]. Japanese Learning and Research, 2014, (3): 59.

[2] Information on https:// en.wikipedia.org/wiki/Formative_assessment

[3] Peng Jin, Xu Minmin. The Application of Performance Evaluation in Japanese Teaching [J]. Japanese Learning and Research, 2016, (6): 74. 